\title{
LES PROVINCES D'EUROPE CENTRALE (APRÈS 1989)
}

Karel BeráNEK, Akta filozofické fakulty pražské univerzity. Acta facultatis philosophicae universitatis pragensis, 1641-1655, 1664-1670. Prague, Univerzita Karlova, 1994. $11 \times 19,322 \mathrm{p}$.

Ivana Čornejoví, Tovaryšstvo Jězíšovo. Jezuité v Čechách. Prague, Mladá fronta (Kolumbus), 1995. $10 \times 16,247 \mathrm{p}$.

Ivana C̆oRnejovÁ et Anna FeChTNerová, Životopisný slovník pražské univerzity. Filozofická a teologická fakulta 1654-1773. Prague, Univerzita Karlova, 1986. $14 \times 21$, LVI-600 p.

Gábor Farkas, István Monok, Annamaria PozSÁr et András VARGa, Magyarorzsági jezsuita könyvtárak 1711-ig. 2 vol. Szeged, Scriptum, 1990 et 1997. $24 \times 15$, xIv-330 p. et 376 p.

Anna Fechtnerová, Rectores collegiarum Societatis Iesu in Bohemia, Moravia ac Silesia usque ad annum mDCCLXXII iacentum. I-II. Prague, Bibliotheca nationalis Pragensis, 1993. $16 \times 10,622$ p., ill.

Ludwik GrzEBIEn, S.J., Slownik jezuitów polskich, 1564-1990. 12 vol. Cracovie, 1993. $16 \times 26$.

Francesco Gul, I Gesuiti e la rivoluzione boema. Alle origini della guerra dei trent'anni. Milan, Franco Angeli, 1989. $14 \times 22,432$ p.

Jezsuita okmánaytár I/1, I/2. Erdélyt és Magyarországot érintö iratok, 1601-1606. Szeged, József Attila Tudományegyetem, 1995. 16,5 × 23,5, xxxv-408 p.

Jezuiti in Slovenskem. Zbornik simpozia. Ljubljana, Provincia lat Slovenske province Družbe Jezusove, 1992. $14 \times$ 19,5, 296 p. (Redovnistvo na Slovenskem Jezuiti, 3).

Emil KraPKa, S.J., et Vojtech Mrkula, S.J., Dejiny Spoločnosti Ježišovej na Slovensku. Cambridge, ON, Dobrá kniha, 1990. $16 \times 18,5,562$ p.

Felicjan Paluszkiewicz, S.J., Maly slownik jezuitów w Polsce. Varsovie, Bobolanum, $1995.15 \times 21,262 \mathrm{p}$.

István György TớtH, Relationes missionariorum de Hungaria et Transylvania, 1627-1707. Budapest/Rome, Bibliotheca Academiae Hungariae in Roma, 1994. $16 \times 24,495$ p. (Fontes, 1).

En Europe centrale et orientale, entendue ici comme l'ancienne «Europe de l'Est ", l'histoire des jésuites s'écrit aujourd'hui d'abord, semble-t-il, de l'intérieur de la Compagnie. 1989 marque ici un vrai tournant: à partir de cette date

Revue de synthèse : $4^{e}$ S. $\mathrm{n}^{\text {os }} 2-3$, avr.-sept. 1999, p. 469-473. 
commencent à être publiés des travaux qui documentent la répression dont l'ordre fut l'objet pendant le stalinisme et les difficiles conditions de son existence parfois clandestine. La revue polonaise Bobolanum propose ainsi, en 1991, un état des lieux des provinces jésuites de Hongrie, de Bohême et de Pologne depuis $1950^{1}$. En Hongrie, il est significatif que le premier volume du vaste projet d'édition Anima una (huit volumes parus en 1995) consacré à l'histoire de la Compagnie de Jésus retrace les destinées de la province hongroisse de 1944 à $1990^{2}$. Ce livre reprend en hongrois un ouvrage publié d'abord en allemand ${ }^{3}$, dont il existe aussi une présentation résumée en français ${ }^{4}$. Des synthèses rédigées par des auteurs jésuites, brèves ou détaillées, couvrant des périodes précédentes ou toute l'histoire de la Compagnie sont parues en Slovénie (Jezuiti in Slovenskem), en République tchèque ${ }^{5}$, de même que deux dictionnaires historiques et biographiques en Pologne (Felicjan Paluszkiewicz et Ludwik Grzebien). L'histoire des jésuites en Slovaquie, publiée au Canada par Emil Krapka et Vojtech Mikula, mérite une mention particulière pour l'abondance et la précision des sources et de la bibliographie de référence, qui peuvent utilement servir au chercheur ignorant le slovaque et le hongrois. La première partie retrace les débuts de l'ordre en Haute-Hongrie, sur le territoire de la Slovaquie contemporaine, où le premier collège de Trnava (Nagyszombat) est fondé en 1561, et deviendra université grâce à Péter Pázmány en 1635. L'intérêt du livre, de ton apologétique, est d'ordre encyclopédique puisqu'il couvre l'ensemble des activités de la Compagnie jusqu'en 1990, allant de la participation des jésuites à l'encadrement paroissial au XvII ${ }^{c}$ et au XviII ${ }^{c}$ siècle, de leurs missions, de l'histoire de chaque collège et de chaque résidence, des confréries et congrégations mariales, de l'enseignement et des imprimeries aux œuvres publiées par des auteurs jésuites et à la gestion des biens de la Compagnie.

La part prise par cette historiographie interne dans l'ensemble des travaux concernant la Compagnie de Jésus paraît cependant différer selon les pays. Elle serait presque intégrale en Pologne où les publications sur l'ordre, qui dernièrement représentent surtout des articles ou des monographies sur des collèges, sont presque toutes dues à des jésuites. La Croatie et la Slovénie connaissent une situation analogue, bien que le nombre des parutions y soit incomparablement plus faible. Ce serait presque l'inverse en Hongrie et en République tchèque. L'histoire universitaire et profane de la Compagnie de Jésus ne doit donc pas être sous-estimée. Cependant, elle se heurte à deux principaux obstacles qui, quoique leur poids ne soit pas partout identique, ont déterminé directement ou indirectement les angles

1. Bobolanum, 3, 1991, en polonais. Voir, en part., les articles des PP. Petr Koláŕ et Emmerich András sur les jésuites de Tchécoslovaquie et de Hongrie.

2. Antal Pálos, Viharon, vészen át. Rövid áttekintés a Jézus Társasága magyar rendtartományanak életeröl a II. Világháború után (1944-1990)), Kecskemét, 1992 (Anima könyvek, 1).

3. ID., Durch Sturm und Bedrängnis. Kurzen Überblick über das Leben der ungarischen Ordensprovinz der Gesellschaft Jesu nach dem II. Weltkrieg, 1944-1990, Vienne, Ungarischen Kirchensoziologischen Institut, 1990.

4. ID., « Un long hiver. Les jésuites en Hongrie de 1944 à 1990 ", Vie consacrée, t. LXIII, 1991, p. $97-117$.

5. František Němec, S.J., Tovaryšstvo. Stručnỹ průřez dějinami jezuitského rádu do roku 1947, Brno, Societas, 1994. 
d'attaque des chercheurs laïcs. D'une façon générale, sous les régimes communistes, la possibilité d'écrire et surtout de publier, à l'intérieur de ces pays, des travaux d'histoire religieuse dépendait des dispositions du pouvoir et du degré de répression ou au contraire de tolérance concernant les églises. Les situations ont beaucoup varié selon les cas et la chronologie. Dans ce contexte politique, l'histoire savante des jésuites n'a pas droit de cité en tant que telle, sauf à séculariser son objet. On peut situer dans cette perspective les travaux publiés partout sur l'histoire de l'éducation, des collèges et des universités, et sur celle de l'érudition et de la littérature néolatine. Une seconde entrave, ancienne et plus insidieuse, conduit à ne s'intéresser à l'histoire des jésuites qu'en la nationalisant. L'historiographie interne à la Compagnie ne fait d'ailleurs pas toujours exception : le livre de Krapka et Mikula signalé plus haut sur l'histoire des jêsuites en Slovaquie s'inscrit pleinement dans une optique de réhabilitation et de réintégration de l'Ordre dans la nation slovaque. La perception de la place tenue par les jésuites dans l'histoire nationale, bien qu'elle ne fasse nulle part l'unanimité, n'en continue pas moins de constituer la toile de fond de la réception des études sur la Compagnie. Il existe ou a existé, dans chaque pays de l'Europe centrale et orientale, un discours dominant sur la Compagnie de Jésus. En Hongrie, en Pologne, en République tchèque, un antijésuitisme virulent s'est forgé dès le début du $\mathrm{xxx}^{\mathrm{e}}$ siècle. Comme ailleurs, il peut s'enraciner dans l'héritage des Lumières et le romantisme, qui l'intègre aux débats sur les nations, en renouvelle profondément la substance et les orientations. Mais cet antijésuitisme hongrois, tchèque et même polonais est en outre contemporain des luttes menées, en Hongrie, en Pologne et en Bohême, pour la renaissance de chaque nation et la reconnaissance de ses droits politiques, historiques ou territoriaux. La persistance, plus que des modèles des histoires nationales, qui eux sont mis en cause depuis 1989, de ceux des identités nationales, ne suffit pourtant pas à expliquer la permanence, vis-à-vis du passé de la Compagnie de Jésus, d'une animosité ou d'un désintérêt plus ou moins marqué, un discours positif étant presque toujours l'apanage de ses défenseurs, souvent religieux ou catholiques militants. L'essentiel est d'avoir attribué aux jésuites la place d'un élément central dans le mythe du destin national. Cette place est directement tributaire de celle faite, dans ces mythes, aux églises et aux confessions catholiques et protestantes. En Pologne, où la virulence antijésuite s'inscrivait dans le débat sur les causes de la décadence et de la perte d'indépendance de la nation, le rôle majeur conféré progressivement à l'Église catholique dans l'identité nationale infléchit au $\mathrm{xx}^{\mathrm{e}}$ siècle le regard sur les jésuites dans un sens positif ou neutre. Andrzej Siwek a fait dernièrement l'utile historique des polémiques dans ce pays, en présentant leurs principaux arguments ${ }^{6}$. Dans les pays de l'ancienne monarchie autrichienne, le moment clé des controverses identitaires concernant la Compagnie est celui de la reprise en mains par les Habsbourg au $\mathrm{XVII}^{\mathrm{e}}$ et au XVIII ${ }^{\mathrm{e}}$ siècle, qui est en Hongrie le temps de la Contre-Réforme, et en République tchèque - comme en Slovénie - celui de la " recatholicisation " générale. Le cas tchèque est le plus tranché : les polémiques sur l'action négative de l'Église se rallument aujourd'hui au moindre prétexte, et pour le grand public les jésuites peuvent toujours facilement incarner les destructeurs de la culture nationale.

6. Andrzej Srwek, «Spory o Jezuitów w polskiej historiografii 1795-1918 », Studia historyczne, t. XXXIV, 4, 1991, p. 551-568, résumé en anglais. 
Il est symptomatique de cet état de choses que l'on n'ait disposé en tchèque avant 1995 que des deux synthèses publiées par Tomás Václav Bílek en 1873 et 1896, écrites d'ailleurs dans un esprit contraire à la Compagnie. On disposait en revanche d'ouvrages plus récents en hongrois $^{7}$ et en polonais ${ }^{8}$. Le livre publié il y a quatre ans par Ivana Cornejová mérite à ce titre déjà d'être signalé, même s'il s'adresse aussi à un public de non-spécialistes. L'auteur y replace, dans le contexte général de la fondation de saint Ignace, l'histoire des jésuites depuis leur arrivée en Bohême en 1556 , en insistant sur la période des $\mathrm{XvII}^{\mathrm{e}}$ et $\mathrm{XVII}{ }^{\mathrm{e}}$ siècles, et ne consacre que trois pages au $\mathrm{XIX}^{\mathrm{e}}$ siècle. Elle y résume les résultats de ses recherches, publiées surtout dans des revues en tchèque. Comme Siwek pour la Pologne, Cornejovả discute aussi, au chapitre XIV intitulé «Ceux qui ne connaissaient ni le sentiment, ni l'amour, ni la moindre humanité, ou la seconde vie de l'ancienne Compagnie » (p. 216-234), les stéréotypes négatifs qui leur sont liés dans le contexte tchèque. Cette historienne est presque seule dans son pays, avec deux ou trois archivistes et bibliothécaires, à se consacrer depuis plus de quinze ans à l'histoire des jésuites, qu'elle a longtemps abordée sous l'angle privilégié de l'histoire de l'université de Prague et du collège Saint-Clément. Elle est aussi le coauteur, avec Anna Fechtnerová, d'un important usuel de prosopographie, un dictionnaire biographique des professeurs et des étudiants des facultés de théologie et de philosophie de cette même université au Xvil et au XVIII siècle. A. Fechtnerová l'a complété par un second dictionnaire, celui des recteurs des collèges de Bohême, de Moravie et de Silésie jusqu'en 1773. Sa bibliographie de référence et sa présentation bilingue en latin et en tchèque permettent un usage au-delà des frontières de l'ancienne province de Bohême.

Les autres travaux touchant à l'histoire des jésuites en République tchèque sont à chercher souvent dans des actes de colloques sur les XVII ${ }^{e}$ et $x{ }^{e} I^{e}$ siècles, tel celui consacré à l'érudit et historiographe Bohuslav Balbín ${ }^{9}$. Particulièrement intéressantes sont la contribution de I. Cornejová (p. 23-32) sur la relève après 1648 des premières générations de jésuites surtout étrangers par des natifs du royaume de Bohême, et celle de Marie Pavlíková (p. 222-231) qui reconstitue la participation active de Balbín aux Acta Eruditorum de Leipzig. Stanislav Sousedík nous montre, quant à lui, dans la seconde partie de son livre passionnant sur la philosophie en Bohême, comment les jésuites de l'université de Prague ont, les premiers, introduit en Bohême un enseignement des principes de Christian Weiss ${ }^{10}$. Il analyse, un peu avant dans ce même livre (chap. I, p. 100-139), la philosophie de Rodrigo Arriaga replacée dans le contexte intellectuel centre-européen. À ce même Arriaga sont consacrés les actes (en allemand) d'un colloque organisé par cet auteur à Prague en $1996^{11}$.

7. Béla Bangha, S.J., A négyszázéves Jézustársaság, Budapest, 1940.

8. James Brodrick et al., Powstanie i rozwój Towarystwa Jezusowego, Cracovie, 1969.

9. Bohuslav Balbín a kultura jeho doby v Čechách, Sborník z konference Památniku národního písemnictví, Prague, Památník národního pisemnictví, 1992.

10. Stanislav Sousediא, Filosofie v Ceských zemich mezi středovĕkem a osvícenstvím, Prague, Vyšehrad, 1997, chap. IIt, p. 262 sqq.

11. Rodrigo de Arriaga Philosoph und Theologe, Hrsg. Tereza SAxLová et Stanislav SouSEDiK, Prague, Karolinum, 1998. 
L'histoire de l'enseignement constitue, comme il a déjà été dit, un des axes forts et continus des publications traitant directement, et plus souvent indirectement de l'histoire de la Compagnie de Jésus en Europe centrale et orientale. On peut y rattacher le recueil en latin d'actes de la faculté de philosophie de Prague, que vient de publier Karel Beránek, qui contient les registres des professeurs et des étudiants et le calendrier des promotions et des soutenances publiques. L'histoire de l'érudition est une autre voie empruntée par les chercheurs, tout particulièrement en Hongrie où existe, à Szeged et à Budapest, une dynamique très importante d'histoire des bibliothèques et des humanistes, et une tradition ancrée d'éditions de textes littéraires en latin. Un recueil tout à fait intéressant de poésies latines composées par des pères de la province de Hongrie au XVIII ${ }^{c}$ siècle permet de commencer une réflexion comparative sur les fonctions de cette littérature et sur son rôle certainement éminent dans la construction des références patriotiques et historiques dans les pays de la monarchie des Habsbourg ${ }^{12}$. Il faut signaler encore le recueil présenté par Mihály Balázs, Tamás Kruppa, István Dávid Lázár et Lászlo Lukács, contenant la correspondance latine des jésuites hongrois et transylvains avec des lettrés européens (Jezsuita okmánaytár), et les inventaires des bibliothèques des collèges jésuites de Kassa (aujourd'hui Kosice), Pozsony (Bratislava), Sárospatak, Turóc et Ungvár (Magyarorzsági jezsuita könyvtárak).

L'histoire des missions est ici présente par au moins deux titres. L'académie hongroise de Rome a entrepris de publier les documents concernant la province de Hongrie conservés aux archives de la Compagnie de Jésus. Le premier volume paru est dû à István György Tóth et contient les relations des missionnaires en Hongrie et en Transylvanie au xvir siècle. Les missions intérieures restent malheureusement un sujet que les chercheurs tchèques n'ont pas ou ont peu abordé. Ce qui n'est pas vrai des missions extérieures, pour lesquelles les éditions de textes de Zdeněk Kalista, dans l'entre-deux-guerres, proposaient un modèle partiel, puisqu'il s'agissait de rendre publiques les correspondances des missionnaires de Bohême en ExtrêmeOrient, et non d'analyser ou d'illustrer les structures et les pratiques de l'entreprise missionnaire. C'est dans cette lignée que Josef Kolmaš vient de publier la correspondance de Karel Slavíček. Elle contient ses lettres de Chine, et d'autres missives adressées à des astronomes européens de son temps, en latin ou à l'occasion en allemand, et en traduction tchèque ${ }^{13}$.

Enfin, la thèse de Francesco Gui à l'université de La Sapienza, si elle pêche par une méconnaissance assez manifeste du contexte tchèque et centre-européen, propose une analyse remarquable des théories jésuites sur le pouvoir et la souveraineté et complète, à bien des égards, les travaux plus anciens de Robert Bireley.

Marie-Elizabeth Ducreux (février 1999).

12. Lázslo SzöRÉnYI, Hunok és jezsuitak, Budapest, Amfipressz, 1993.

13. Josef Kolmaš, Karel Slavíček S.I. Listy z Cíny do vlasti a jiná korespondence $s$ evropskými hvězdári, 1716-1735, Prague, Vyšehrad, 1995. 